\title{
Prognostic value of age adjusted segment involvement score as measured by coronary computed tomography: a potential marker of vascular age
}

\author{
Chadi Ayoub ${ }^{1,2,3}$ (1) $\cdot$ Leonard Kritharides ${ }^{3,4} \cdot$ Yeung Yam $^{1} \cdot$ Li Chen $^{1} \cdot$ Alomgir Hossain $^{1} \cdot$ Stephan Achenbach $^{5}$. \\ Mouaz H. Al-Mallah ${ }^{6}$. Daniele Andreini ${ }^{7}$. Daniel S. Berman ${ }^{8} \cdot$ Matthew J. Budoff $^{9}$. Filippo Cademartiri ${ }^{10}$. \\ Tracy Q. Callister ${ }^{11} \cdot$ Hyuk-Jae Chang ${ }^{12} \cdot$ Kavitha Chinnaiyan $^{13} \cdot$ Ricardo C. Cury $^{14} \cdot$ Augustin Delago $^{15}$. \\ Allison Dunning ${ }^{16}$. Gudrun Feuchtner ${ }^{17}$. Millie Gomez ${ }^{18}$. Heidi Gransar ${ }^{8}$. Martin Hadamitzky ${ }^{19}$. \\ Joerg Hausleiter ${ }^{19}$. Niree Hindoyan ${ }^{18}$. Philipp A. Kaufmann ${ }^{20}$. Yong-Jin Kim ${ }^{21}$. Jonathon Leipsic ${ }^{22}$. Erica Maffei ${ }^{10}$. \\ Hugo Marques $^{23}$. Gianluca Pontone ${ }^{7} \cdot$ Gilbert Raff $^{13} \cdot$ Ronen Rubinshtein $^{24}$ • Leslee J. Shaw ${ }^{25} \cdot$ Todd C. Villines $^{26}$. \\ James K. Min ${ }^{18} \cdot$ Benjamin J. W. Chow ${ }^{1,27}$
}

Received: 14 September 2017 / Accepted: 18 May 2018 / Published online: 24 May 2018

(c) Springer Japan KK, part of Springer Nature 2018

\begin{abstract}
Extent of coronary atherosclerotic disease (CAD) burden on coronary computed tomography angiography (CCTA) as measured by segment involvement score (SIS) has a prognostic value. We sought to investigate the incremental prognostic value of 'age adjusted SIS' (aSIS), which may be a marker of premature atherosclerosis and vascular age. Consecutive patients were prospectively enrolled into the CONFIRM (Coronary CT Angiography EvaluatioN For Clinical Outcomes: An InteRnational Multicentre) multinational observational study. Patients were followed for the outcome of all-cause death. aSIS was calculated on CCTA for each patient, and its incremental prognostic value was evaluated. A total of 22,211 patients [mean age $58.5 \pm 12.7$ years, $55.8 \%$ male) with a median follow-up of 27.3 months (IQR 17.8, 35.4)] were identified. After adjustment for clinical factors and presence of obstructive CAD, higher aSIS was associated with increased death on multivariable analysis, with hazard ratio (HR) 2.40 (1.83-3.16, $p<0.001), C$-statistic $0.723(0.700-0.756)$, net reclassification improvement (NRI) $0.36(0.26-0.47, p<0.001)$, and relative integrated discrimination improvement (IDI) $0.33(p=0.009)$. aSIS had HR $3.48(2.33-5.18, p<0.001)$ for mortality in those without obstructive CAD, compared to HR $1.79(1.25-2.58$, $p=0.02)$ in those with obstructive CAD. In conclusion, aSIS has an incremental prognostic value to traditional risk factors and obstructive CAD, and may enhance CCTA risk stratification.
\end{abstract}

Keywords Coronary $\cdot$ Computed tomography $\cdot$ Atherosclerosis $\cdot$ Prognosis

\section{Introduction}

Coronary computed tomography angiography (CCTA) is recommended in symptomatic individuals for the detection and exclusion of coronary artery disease (CAD) [1], and has a prognostic value [2-4]. Increasing extent of coronary atherosclerosis, as quantified by segment involvement score (SIS) or the synonymous total plaque score (TPS), has been shown to be a predictor of clinical events [5-7]. Rate of

Benjamin J. W. Chow

bchow@ottawaheart.ca

Extended author information available on the last page of the article development of atherosclerotic disease has been shown to be a better predictor of adverse clinical outcomes [8-10]. Hence we devised a score 'age adjusted SIS' (aSIS), which standardizes SIS to the number of evaluable segments and normalizes it to patient age. We hypothesize that aSIS is a surrogate marker of 'vascular age', as it gives greater weighting to segments involved in those who are younger, and so may account for premature atherosclerotic disease.

Previous work demonstrated that aSIS (or as previously termed \%TPS/age) had an incremental prognostic value over risk factors and obstructive CAD for MACE [11]. We sought to externally validate the prognostic value of aSIS in the large prospective multinational CONFIRM (COronary 
Computed Tomography Angiography Evaluation for Clinical Outcomes: An InteRnational Multicentre Registry) cohort.

\section{Materials and methods}

\section{Study population}

Consecutive patients undergoing CCTA were prospectively enrolled into the CONFIRM (COroNary CT Angiography Evaluation For Clinical Outcomes: An InteRnational Multicenter Registry). The design of the registry has been described in depth previously [12]. Inclusion criteria were adults ( $\geq 18$ years) referred for clinically suspected CAD who underwent $\geq 64$-detector row CCTA examination between February 2003 and September 2010 in twelve centers in six countries (Canada, Germany, Italy, Korea, Switzerland, and the United States). This study complies with the Declaration of Helsinki, and all centers had institutional review board approval for patient enrollment and follow-up. Only patients who provided informed consent were included.
Patients with a history of heart transplantation and congenital heart disease were excluded. To ensure there was no duplication of patients, we removed patients who had been analyzed in our previous study [11]. In addition, patients with $<11$ segments reported $(n=6464)$ and patients who had missing information about clinical risk factors were removed from analysis. After excluding 7410 patients, a total of 22,211 patients were available for analysis (Fig. 1).

\section{Clinical data}

Patient demographic data, medical history, risk factors, physical data, and indications for CCTA were collected before each CCTA examination in site-specific case report forms. Standardized definitions for cardiovascular risk factors were used [12]. National Cholesterol Education Program (NCEP) risk was calculated using age, gender, symptoms, and risk factors (smoking, hypertension, dyslipidemia, diabetes, and family history of premature CAD) [13-15].

Fig. 1 Study flow diagram

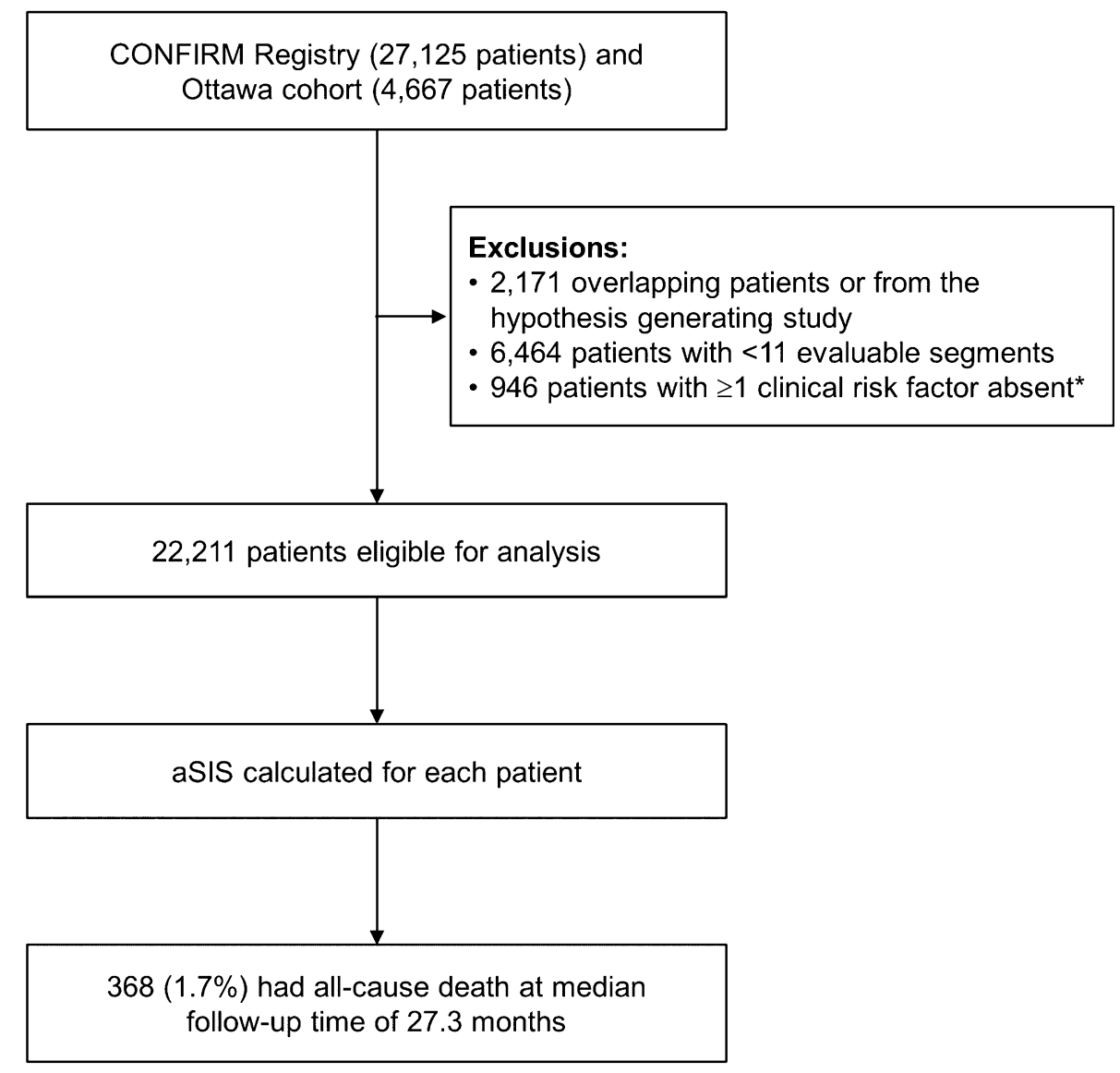

*Smoking, hypertension, dyslipidemia, diabetes, and family history 


\section{CCTA image acquisition and analysis}

CCTAs were performed with $\geq 64$-detector row scanner, and included both single-source and dual-source scanners. Image acquisition, post-processing, and interpretation for CCTAs in the CONFIRM cohort were in compliance with each site's institutional policy or SCCT guidelines $[12,16]$. CAC scores were calculated by the method of Agatston [17]. Standard post-processing techniques were used to determine the presence and extent of CAD, with obstructive CAD defined as a luminal diameter stenosis $\geq 50 \%$. Coronary artery anatomy and the extent of atherosclerotic plaque were assessed using a 17-segment model of the coronary arteries (Fig. 2) [16].

\section{Calculation of aSIS}

SIS was calculated as the total number of coronary segments with atherosclerotic plaque (irrespective of severity). aSIS was calculated as the quotient between SIS and the total number of segments that was evaluable for plaque, multiplied by 100 , and adjusted by dividing by patient age $($ aSIS $=([$ SIS/total number of evaluable segments $] \times 100) /$ age) (Fig. 2). To obtain clinically applicable categorization, the cohort was divided into four categories of aSIS. All aSIS $=0$ (no atherosclerosis) were assigned into the first category, and the remaining were divided into 3 categories based on cutoffs derived from our previous single-center study [11].

\section{Patient follow-up and outcome measure}

All patients were followed for all-cause death, the pre-specified outcome for the CONFIRM registry, by local institutions through a dedicated physician or research nurse or both [12]. Death was ascertained by query of the National Death Index in US sites, and in non-US sites by direct interview or telephone contact with the patient's immediate family or primary physician or review of medical records [12]. As the National Death Index data do not include the cause of death, no data for cardiac death were available for analysis.

\section{Statistical analysis}

Absolute counts and percentages were presented for categorical variables, and continuous variables were presented as mean \pm standard deviation (SD) for normally distributed data and medians [interquartile range (IQR)] for skewed data. The Wilcoxon rank sum test was used for continuous variables and Chi-square test for categorical variables. Univariable and multivariable analyses were
Fig. 2 Coronary artery tree, 17 segment model. In a case of a 45-year-old who has plaque in 3 of 17 segments (circled), SIS would be 3 and aSIS 0.39. Whilst current data would suggest $\mathrm{SIS}<5$ portends lower risk than SIS $\geq 5[2,5]$, applying aSIS re-stratifies this younger patient into the highest risk category, suggesting more extensive $\mathrm{CAD}$ for age

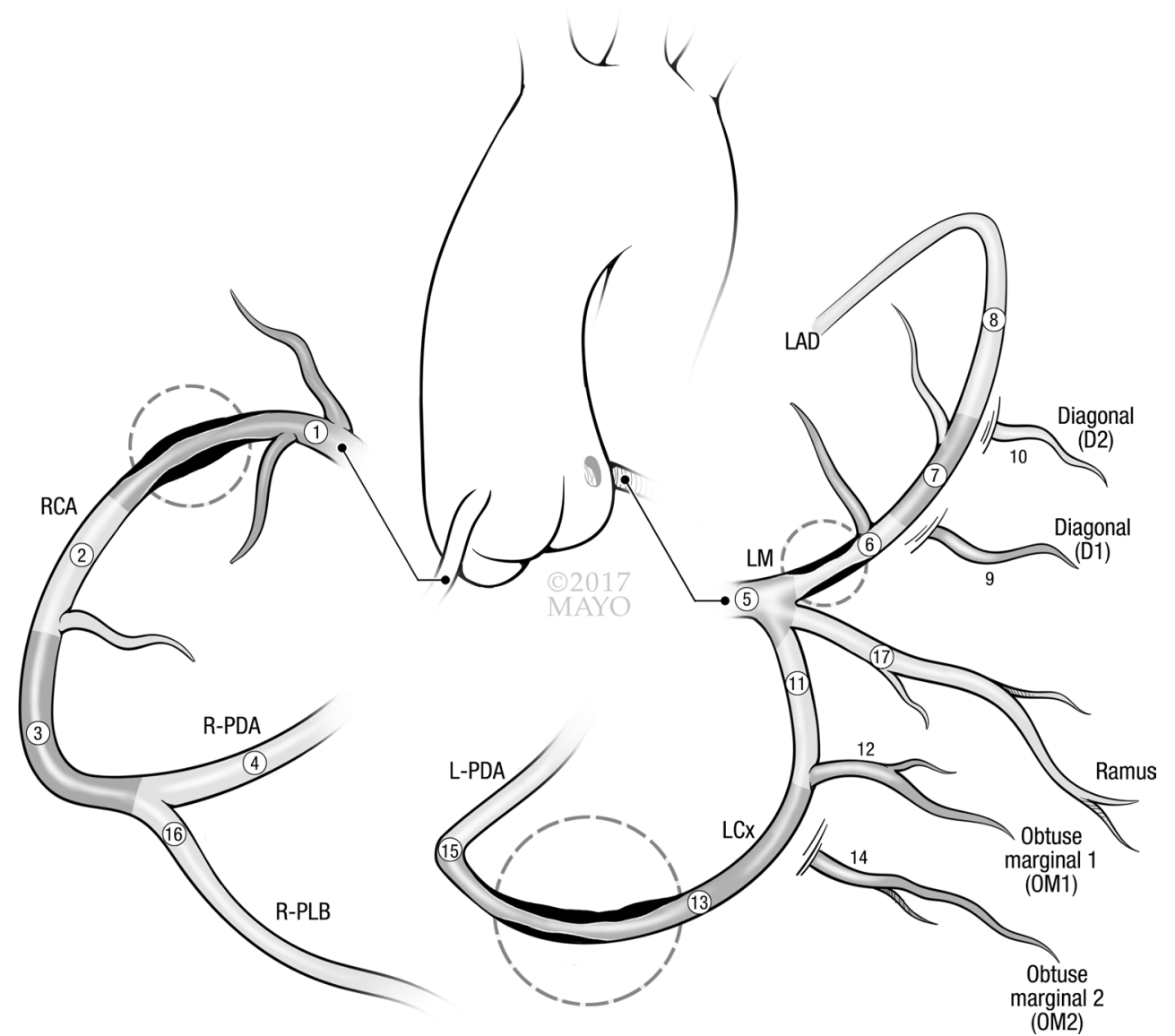


performed to assess the prognostic value of aSIS for allcause death. Any risk factor or CT parameter that had statistically significant $(p<0.05)$ association for mortality on univariable analysis was included in the subsequent multivariable modeling. Cox proportional hazard models were performed for risk-adjusted analyses to evaluate the independent prognostic value of aSIS and construct adjusted survival curves. Statistically significant increases in the global Chi-square value and comparisons with global model fit using likelihood ratio tests were used to assess the incremental prognostic value of models with and without aSIS.

$C$-index of Harrell was assessed to determine the ability of models with aSIS to predict mortality [18]. Improvement in the prediction performance for mortality of a model that adds aSIS to clinical risk factors and presence of obstructive CAD was evaluated with the net reclassification improvement (NRI) index [19]. Category-free NRI which defines upward and downward movement as any change in the predicted probabilities was reported as a measure of discrimination with $95 \%$ confidence intervals, as it is not influenced by correct scaling of the model and is more generalizable [20]. The integrated discrimination improvement (IDI) and relative IDI were calculated to quantify the added predictive ability of models that included obstructive CAD and aSIS sequentially to clinical predictors. SAS Version 9.3 software (SAS Institute Inc., Cary, NC) was used to perform statistical calculations, with statistical significance defined as $p<0.05$.

\section{Results}

\section{Patient characteristics}

A total of 22,211 patients (mean age $58.5 \pm 12.7$ years, $55.8 \%$ male) were identified with median follow-up time of 27.3 months (IQR 17.8, 35.4) (Table 1). The follow-up rate for mortality was $96.5 \%$ in the CONFIRM cohort. Patients included in the analysis had a median aSIS of 0.16 (IQR $0.00,0.47$ ), and median SIS of 1.0 (IQR 0.0, 4.0). There was no visible coronary atherosclerosis (SIS and aSIS $=0$ ) in $8763(39.5 \%)$ patients.

Based on the previous work, patients were stratified into 4 categories (aSIS $=0,0.001-0.314,0.314-0.699, \geq 0.700$ ) [11]. Patients falling into, respectively, higher aSIS category had increasing rates of cardiovascular risk factors (diabetes, hypertension, hypercholesterolemia, smoking, and family history) and were more likely to be male (Table 1). Additionally, those in the highest aSIS category $(\geq 0.700)$ were more likely to have obstructive CAD $(72 \%)$.

\section{Clinical outcome}

A total of 368 patients had the clinical outcome of death (Figs. 3, 4). Forty-nine (0.6\%) events were observed in the aSIS $=0$ category $(\mathrm{AER}=0.20 \%) .106$ events $(2.0 \%)$ were observed in the aSIS $<0.314$ category (AER $=0.61 \%$ ), 116 $(2.3 \%)$ in the aSIS $0.314-0.699$ category $(\mathrm{AER}=0.78 \%)$, and $97(3.2 \%)$ in the aSIS $\geq 0.700$ category $(\mathrm{AER}=1.08 \%)$ (Fig. 4).

\section{Univariable analysis}

Comparing patients with and without the clinical outcome, those who died were more likely to have hypertension [HR 1.93 (1.56-2.40), $p<0.001$ ], diabetes [HR $1.74(1.38-2.19)$, $p<0.001$ ], and smoking history [HR 1.88 (1.52-2.32), $p<0.001$ ] (Table 2). History of dyslipidemia and chest pain appeared to have lower mortality. In patients with dyslipidemia, this observation might be attributed to statin therapy. The protective nature of chest pain may be due to higher prevalence of non-cardiac chest pain, and treatment of symptomatic CAD with either optimal medical therapy or revascularization.

Number of segments with obstructive CAD ( $\geq 50 \%$ stenosis) was associated with HR 1.28 (1.23-1.33) for all-cause mortality, which was similar to, but slightly more predictive than that of SIS, with HR $1.22(1.18-1.25)$, both $p<0.001$. aSIS was most predictive of mortality with HR 3.68 (2.97-4.56), $p<0.001$, followed by presence of obstructive CAD, with HR 3.11 (2.54-3.82), $p<0.001$ (Table 2). In subjects $\leq 50$ years of age ( $n=5702,36$ deaths) aSIS had HR 4.62 (2.62-8.15), whereas in those $>50$ years old ( $n=16,509,332$ deaths) HR was 3.22 (2.53-4.11), both $p<0.001$.

\section{Multivariable analysis}

Cox proportional hazard modeling was performed to assess the prognostic value of aSIS over clinical predictors and obstructive CAD (Table 3). aSIS had HR 2.40 (1.83-3.16) for all-cause death, $p<0.001$, and Harrell $C$-statistic 0.723 (0.700-0.756) when applied in addition to clinical risk factors and obstructive CAD ( $\geq 50 \%)$. Use of aSIS category to predict all-cause death was associated with HR of $1.52(1.36-1.71), \mathrm{p}<0.001$ and Harrell $C$-statistic 0.735 (0.707-0.762).

\section{Reclassification statistics}

Category-free NRI was used to examine the ability of aSIS to appropriately reclassify patient risk for death. aSIS as a continuous variable had a category-free NRI of $0.36(0.26-0.47), p<0.001$, for all-cause death when used 
Table 1 Patient characteristics

\begin{tabular}{|c|c|c|c|c|c|c|}
\hline & $\begin{array}{l}\text { All patients } \\
(n=22,211)\end{array}$ & aSIS $=0(n=8763)$ & $\begin{array}{l}\text { aSIS } 0.001-0.313 \\
(n=5420)\end{array}$ & $\begin{array}{l}\text { aSIS 0.314-0.699 } \\
(n=5009)\end{array}$ & $\begin{array}{l}\text { aSIS } \geq 0.700 \\
(n=3019)\end{array}$ & $p$ value \\
\hline $\begin{array}{l}\text { Median follow-up } \\
\text { (months) }\end{array}$ & $24.9(17.8,35.4)$ & $28.0(17.9,37.8)$ & $27.5(18.0,36.1)$ & $26.5(17.9,33.3)$ & $25.9(17.5,33.2)$ & $<0.001$ \\
\hline Age & $58.5 \pm 12.7$ & $51.9 \pm 12.4$ & $61.8 \pm 11.2$ & $63.4 \pm 10.9$ & $63.0 \pm 10.6$ & $<0.001$ \\
\hline Male gender & $12,403(55.8 \%)$ & $3967(45.3 \%)$ & $3016(55.6 \%)$ & $3186(63.1 \%)$ & $2234(74.0 \%)$ & $<0.001$ \\
\hline $\begin{array}{l}\text { Body mass index } \\
\left(\mathrm{kg} / \mathrm{m}^{2}\right)^{\mathrm{a}}\end{array}$ & $27.1 \pm 5.0$ & $26.7 \pm 5.1$ & $27.0 \pm 5.0$ & $27.2 \pm 4.9$ & $27.8 \pm 5.0$ & $<0.001$ \\
\hline \multicolumn{7}{|l|}{ Cardiac risk factors } \\
\hline Smoker/ex-smoker & $6471(29.1 \%)$ & $2247(25.6 \%)$ & $1445(26.7 \%)$ & $1569(31.3 \%)$ & $1210(40.1 \%)$ & $<0.001$ \\
\hline Hypertension & $11,585(52.2 \%)$ & $3767(43.0 \%)$ & $2955(54.5 \%)$ & $2918(58.3 \%)$ & $1945(64.4 \%)$ & $<0.001$ \\
\hline Dyslipidemia & $12,362(55.7 \%)$ & $4016(45.8 \%)$ & $3054(56.3 \%)$ & $3144(62.8 \%)$ & $2148(71.1 \%)$ & $<0.001$ \\
\hline Diabetes & $3876(17.5 \%)$ & $1057(12.1 \%)$ & $949(17.5 \%)$ & $1119(22.3 \%)$ & $751(24.9 \%)$ & $<0.001$ \\
\hline $\begin{array}{l}\text { Family history of } \\
\text { CAD }\end{array}$ & $7979(35.9 \%)$ & $2911(33.2 \%)$ & $1893(34.9 \%)$ & $1906(38.1 \%)$ & $1269(42.0 \%)$ & $<0.001$ \\
\hline \multicolumn{7}{|l|}{ Symptoms } \\
\hline Chest pain ${ }^{\mathrm{b}}$ & $12,281(55.3 \%)$ & $5396(61.6 \%)$ & $2750(50.7 \%)$ & $2508(50.1 \%)$ & $1630(54.0 \%)$ & \\
\hline $\begin{array}{l}\text { Non-anginal chest } \\
\text { pain }\end{array}$ & $1636(8.6 \%)$ & $673(8.6 \%)$ & $383(8.9 \%)$ & $342(8.5 \%)$ & $238(8.6 \%)$ & 0.152 \\
\hline Atypical angina & $7596(40.1 \%)$ & $3638(46.2 \%)$ & $1675(38.9 \%)$ & $1379(34.3 \%)$ & $904(32.8 \%)$ & $<0.001$ \\
\hline Typical angina & $3049(16.1 \%)$ & $1085(13.8 \%)$ & $689(16.0 \%)$ & $787(19.6 \%)$ & $488(17.7 \%)$ & $<0.001$ \\
\hline Dyspnea $^{\mathrm{c}}$ & $5079(28.9 \%)$ & $1990(27.5 \%)$ & $1170(29.1 \%)$ & $1174(31.3 \%)$ & $745(28.7 \%)$ & 0.001 \\
\hline \multicolumn{7}{|l|}{$\mathrm{NCEP}^{\mathrm{d}}$} \\
\hline Low risk $(<10 \%)$ & $6037(27.2 \%)$ & $3609(41.2 \%)$ & $1238(22.8 \%)$ & $819(16.4 \%)$ & $371(12.3 \%)$ & $<0.001$ \\
\hline $\begin{array}{l}\text { Intermediate risk } \\
(10-20 \%)\end{array}$ & $11,610(52.3 \%)$ & $3945(45.0 \%)$ & $3132(57.8 \%)$ & $2885(57.6 \%)$ & $1648(54.6 \%)$ & $<0.001$ \\
\hline High risk $(>20 \%)$ & $4564(20.5 \%)$ & $1209(13.8 \%)$ & $1050(19.4 \%)$ & $1305(26.1 \%)$ & $1000(33.1 \%)$ & $<0.001$ \\
\hline \multicolumn{7}{|l|}{ Medications } \\
\hline Beta-blocker & $4093(30.9 \%)$ & $1257(23.1 \%)$ & $983(31.9 \%)$ & $1006(37.3 \%)$ & $847(42.3 \%)$ & $<0.001$ \\
\hline Aspirin & $5479(41.4 \%)$ & $1561(28.6 \%)$ & $1418(46.1 \%)$ & $1462(54.2 \%)$ & $1038(51.8 \%)$ & $<0.001$ \\
\hline ACE-inhibitor & $2073(15.7 \%)$ & $561(10.3 \%)$ & $477(15.5 \%)$ & $506(18.7 \%)$ & $529(26.4 \%)$ & $<0.001$ \\
\hline Statin & $5211(39.3 \%)$ & $1256(23.0 \%)$ & $1319(42.8 \%)$ & $1430(52.9 \%)$ & $1206(60.1 \%)$ & $<0.001$ \\
\hline \multicolumn{7}{|l|}{ LV parameters ${ }^{\mathrm{e}}$} \\
\hline $\begin{array}{l}\text { LV ejection frac- } \\
\text { tion }(\%)\end{array}$ & $62.0 \pm 12.5$ & $60.9 \pm 12.3$ & $62.2 \pm 12.1$ & $62.9 \pm 12.5$ & $62.2 \pm 13.4$ & 0.001 \\
\hline $\begin{array}{l}\text { Normal LVEF } \\
\quad(\geq 50 \%)\end{array}$ & $10,623(85.1 \%)$ & $4158(87.3 \%)$ & $2432(85.4 \%)$ & $2437(83.9 \%)$ & $1596(81.5 \%)$ & $<0.001$ \\
\hline Obstructive CAD & $5749(25.9 \%)$ & $2(0.0 \%)$ & $1216(22.4 \%)$ & $2358(47.1 \%)$ & $2173(72.0 \%)$ & $<0.001$ \\
\hline SIS & $1.00(0.00,4.00)$ & $0.00(0.00,0.00)$ & $1.00(1.00,2.00)$ & $4.00(3.00,5.00)$ & $7.00(6.00,9.00)$ & $<0.001$ \\
\hline$\%$ SIS & $8.33(0.00,28.57)$ & $0.00(0.00,0.00)$ & $8.33(7.69,15.38)$ & $28.57(23.08,35.71)$ & $58.33(50.00,72.73)$ & $<0.001$ \\
\hline aSIS & $0.16(0.00,0.47)$ & $0.00(0.00,0.00)$ & $0.18(0.13,0.25)$ & $0.47(0.39,0.58)$ & $0.93(0.80,1.12)$ & $<0.001$ \\
\hline
\end{tabular}

${ }^{\mathrm{a}} n=17,730$

${ }^{\mathrm{b}} n=18,754$

${ }^{\mathrm{c}} n=17,601$

${ }^{\mathrm{d}} 10$-year absolute risk of cardiovascular event

${ }^{\mathrm{e}} n=12,476$

in addition to clinical predictors and obstructive CAD (Table 3). IDI and relative IDI are also reported in Table 3, and taken together, addition of obstructive CAD has a significant incremental reclassification effect over the model of clinical risk factors only, and the addition of aSIS has a further significant incremental reclassification effect over the model of clinical risk factors and obstructive CAD.

Higher aSIS category was also incremental over clinical predictors and obstructive CAD with NRI of 0.34 $(0.24-0.44), p<0.001$. In 2 separate models used to compare 


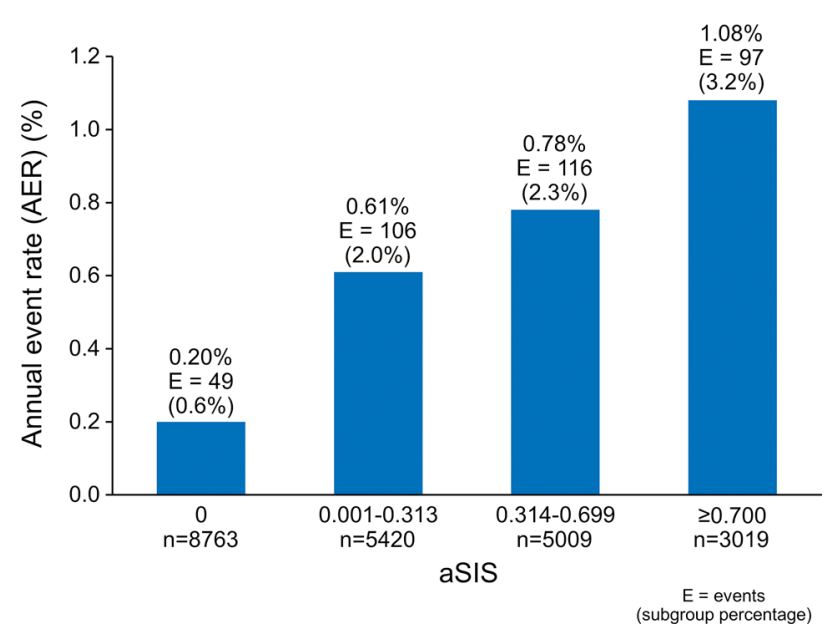

Fig. 3 Annual event rates for mortality by aSIS category for the entire cohort $(n=22,211)$. Mortality comparison between aSIS categories had $p<0.001$ for all comparisons, except between $0.001-0.313$ category and $0.314-0.699$ category $(p=0.05)$

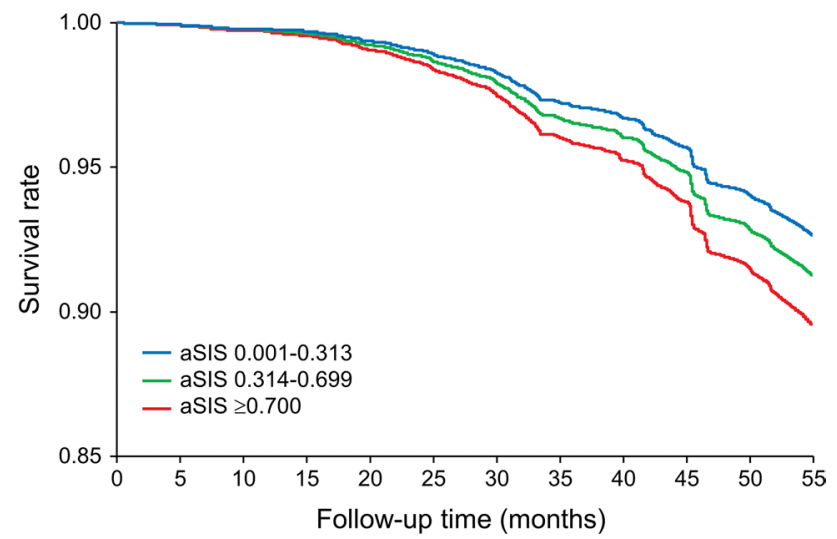

Fig. 4 Risk-adjusted survival curves by aSIS category, $p<0.001$. aSIS $=0$ category, whilst included in the continuous variable analysis, was not included in this figure as it was used as a reference for outcomes for the other aSIS categories

risk reclassification in addition to traditional clinical risk factors, aSIS demonstrated similar ability to reclassify patient risk as the presence of obstructive CAD, with NRI of $0.46(0.36-0.56)$ for the model 'clinical risk + aSIS' versus $0.48(0.37-0.58)$ for the model 'clinical risk + obstructive $\mathrm{CAD}^{\prime}, p<0.001$.

\section{Sub-analysis in patients with obstructive and non-obstructive CAD}

aSIS was associated with highest risk for mortality, with highest hazard ratios for both patients with non-obstructive CAD and obstructive CAD (Tables 4, 5, 6). Importantly, in the population with non-obstructive CAD, aSIS had significantly higher HR for mortality than SIS or age alone.

\section{Discussion}

Using the CONFIRM registry, the independent and incremental prognostic value of aSIS was validated over routine clinical measures and CCTA measure of obstructive CAD. Higher aSIS categories were associated with increased risk of all-cause mortality (HR $2.40(1.83-3.16), p<0.001$, and NRI of 0.36 (0.26-0.47), $p<0.01)$.

Previous work demonstrated that aSIS (also termed \% TPS/age) score has an incremental prognostic value for MACE over traditional risk factors and conventional CCTA assessment of coronary atherosclerosis [11]. We hypothesized that this novel measure, which can be quickly and easily derived from routine clinical CCTA, may be a surrogate marker of coronary vascular age. Although the prevalence of traditional risk factors and obstructive CAD increased with aSIS category, two-thirds of patients in the highest aSIS category had low or intermediate NCEP risk (Table 1); hence confirming the potential limitations of routine clinical risk predictors and the potential utility of aSIS to reclassify patient risk.

\section{CCTA, extent of CAD, and prognosis}

Framingham risk factors have only moderate correlation with atherosclerosis burden; a significant proportion of patients with low and intermediate Framingham risk have coronary atherosclerosis demonstrated by CCTA [21]. Anatomic evaluation of coronary arteries by CCTA allows early identification of coronary artery disease that may be subclinical and undetectable by functional testing, but is often the substrate of MACE [22, 23]. The presence of non-obstructive CAD on CCTA is associated with higher mortality even adjusting for CAD risk factors, with highest risk seen in those with greater extent of non-obstructive CAD [2, 4, 5]. SIS is a simple and reproducible semiquantitative measure quantifying the extent of CAD burden on CCTA (irrespective of degree of stenosis). Extent of CAD is a strong predictor of events [24], and SIS $\geq 5$ on CCTA has been shown to have worse prognosis that is comparable to the presence of obstructive CAD [2, 5].

\section{Coronary vascular age and atherosclerosis that is extensive for age}

SIS and extent of CAD increase with age [25, 26]. Atherosclerosis begins in the early decades of life [27], and may remain clinically silent for decades until plaque erosion and rupture result in clinical events or lesions become obstructive resulting in ischemia. However, individuals with more rapid development of coronary atherosclerosis have 
Table 2 Univariable analysis for mortality

\begin{tabular}{|c|c|c|c|c|}
\hline & All-cause death $(n=368)$ & $\begin{array}{l}\text { No all-cause death } \\
(n=21843)\end{array}$ & Hazard ratio $(95 \% \mathrm{CI})$ & $p$ value \\
\hline Male gender & $218(58.7 \%)$ & $12,187(55.8 \%)$ & $1.12(0.91-1.38)$ & 0.292 \\
\hline Body mass index $\left(\mathrm{kg} / \mathrm{m}^{2}\right)^{\mathrm{a}}$ & $26.0 \pm 5.5$ & $27.1 \pm 5.0$ & $0.98(0.95-1.00)$ & 0.070 \\
\hline \multicolumn{5}{|l|}{ Cardiac risk factors } \\
\hline Smoker/ex-smoker & $140(38.0 \%)$ & $6331(29.0 \%)$ & $1.88(1.52-2.32)$ & $<0.001$ \\
\hline Hypertension & $245(66.6 \%)$ & $11,340(51.9 \%)$ & $1.93(1.56-2.40)$ & $<0.001$ \\
\hline Dyslipidemia & $178(48.4 \%)$ & $12,184(55.8 \%)$ & $0.72(0.59-0.88)$ & 0.001 \\
\hline Diabetes & $101(27.4 \%)$ & $3775(17.3 \%)$ & $1.74(1.38-2.19)$ & $<0.001$ \\
\hline Family history of CAD & $121(32.9 \%)$ & $7858(36.0 \%)$ & $1.24(0.99-1.54)$ & 0.057 \\
\hline NCEP & & & $1.88(1.61,2.19)$ & $<0.001$ \\
\hline Low risk & $45(12.2 \%)$ & $5991(23.3 \%)$ & & \\
\hline Intermediate risk & $194(52.7 \%)$ & $12,317(56.4 \%)$ & & \\
\hline High risk & $129(35.1 \%)$ & $4435(20.3 \%)$ & & \\
\hline Chest pain ${ }^{\mathrm{b}}$ & $161(44.6 \%)$ & $11,754(53.8 \%)$ & $0.64(0.51-0.81)$ & $<0.001$ \\
\hline Dyspnea $^{c}$ & $112(30.4 \%)$ & $4967(22.7 \%)$ & $2.19(1.72-2.79)$ & $<0.001$ \\
\hline Abnormal LVEF $(\leq 50 \%)^{\mathrm{d}}$ & $72(19.6 \%)$ & $1781(8.2 \%)$ & $2.35(1.78-3.11)$ & $<0.001$ \\
\hline Obstructive CAD $(\geq 50 \%)$ & $182(49.5 \%)$ & $5567(25.5 \%)$ & $3.11(2.54-3.82)$ & $<0.001$ \\
\hline Age & $69.0 \pm 12.7$ & $58.3 \pm 12.3$ & $1.09(1.08-1.10)$ & $<0.001$ \\
\hline SIS & $4.00(2.00,6.00)$ & $1.00(0.00,4.00)$ & $1.22(1.18-1.25)$ & $<0.001$ \\
\hline$\%$ SIS & $28.57(14.29,50.00)$ & $8.33(0.00,28.57)$ & $1.03(1.02-1.03)$ & $<0.001$ \\
\hline aSIS & $0.38(0.19,0.73)$ & $0.15(0.00,0.47)$ & $3.68(2.97-4.56)$ & $<0.001$ \\
\hline aSIS category & $2.7 \pm 1.0$ & $2.1 \pm 1.1$ & $1.75(1.59-1.92)$ & $<0.001$ \\
\hline
\end{tabular}

${ }^{\mathrm{a}} n=17,730$

$\mathrm{b}_{n=18,754}$

${ }^{\mathrm{c}} n=17,601$

${ }^{\mathrm{d}} n=12,476$

an increased rate of adverse outcomes [8-10, 28]. Absolute plaque measurements may estimate 10 -year risk which is independent of age; however, adjusting plaque burden to age gives a greater weighting for each involved segment if younger and may be a potential estimate of lifetime risk. For example, a 30-year-old and 60-year-old who have the same plaque burden and CAC theoretically may have the same 5-10 year risk; however, the 30-year-old would have atherosclerotic disease that has developed more rapidly and is more extensive for their age, and aSIS may act as a marker of vascular age and provide enhanced prediction of lifetime risk.

\section{Clinical implications}

The simplicity of SIS gives the potential for it to be calculated by automated software algorithms. Itss adjustment to age as aSIS may offer a method of enhanced risk stratification and prognostication by CCTA. With advancements in CT technology and novel scanning algorithms promising ongoing reduction in radiation dose and increasing use of CCTA, aSIS uses information readily available and easily calculable from clinical scans that may identify patients with 'greater vascular age' or atherosclerosis that is more extensive for age, and at greater risk of mortality. Additionally, aSIS may be a sensitive marker of subclinical (non-obstructive) disease, removing a false sense of security for some at-risk patients, and so improve adherence to preventative measures.

CT evaluation of coronary atherosclerosis impacts downstream testing and management, influences physician behavior, and results in better risk factor modification and increased medical therapy [29-31]. The use of statins has been associated with reduced risk for mortality in patients with non-obstructive disease on CCTA [32, 33]. Bittencourt et al. have shown that extent of plaque detected by CCTA enhances risk assessment, and even patients with nonobstructive disease and SIS $>4$ had significant increase in events; it is thus possible that statins may reduce mortality in patients with higher aSIS [5].

Whilst there is a lack of prospective data, aSIS could be a useful tool for triaging medical therapy. Further prospective studies are needed to understand the clinical role of aSIS, and potential economic benefits. However, 


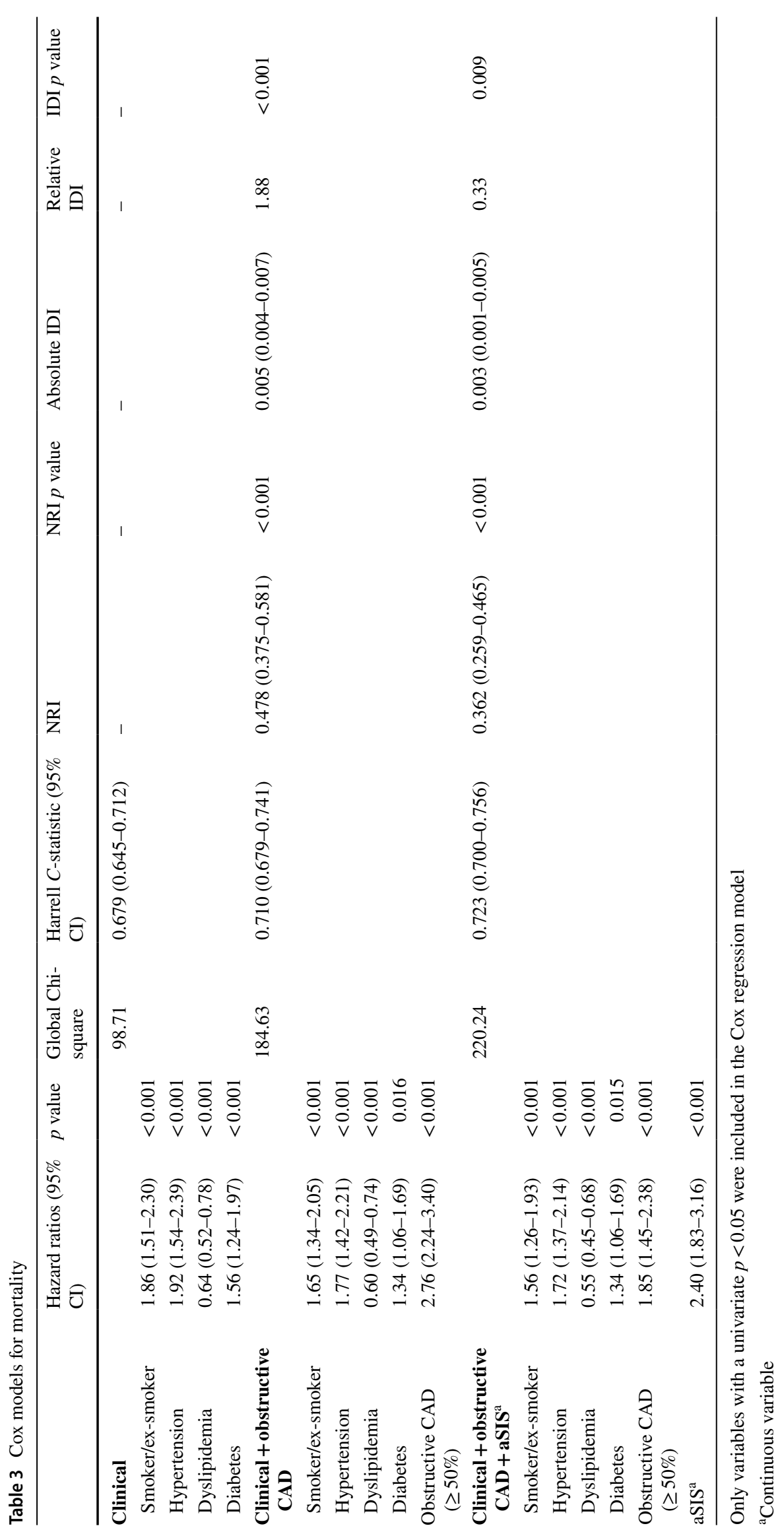


Table 4 Univariable analysis for mortality in patients with non-obstructive CAD and obstructive CAD

\begin{tabular}{|c|c|c|c|c|}
\hline & $\begin{array}{l}\text { Non-obstructive CAD } \\
\text { Hazard ratio }(95 \% \mathrm{CI})\end{array}$ & $p$ value & $\begin{array}{l}\text { Obstructive CAD } \\
\text { Hazard ratio (95\% CI) }\end{array}$ & $p$ value \\
\hline Male gender & $0.99(0.73-1.34)$ & 0.932 & $0.96(0.72-1.27)$ & 0.754 \\
\hline Body mass index $\left(\mathrm{kg} / \mathrm{m}^{2}\right)^{\mathrm{a}}$ & $0.92(0.88-0.96)$ & $<0.001$ & $1.01(0.97-1.04)$ & 0.738 \\
\hline \multicolumn{5}{|l|}{ Cardiac risk factors } \\
\hline Smoker/ex-smoker & $1.52(1.13-2.04)$ & 0.005 & $1.78(1.31-2.42)$ & $<0.001$ \\
\hline Hypertension & $1.33(0.98-1.81)$ & 0.070 & $2.18(1.61-2.95)$ & $<0.001$ \\
\hline Dyslipidemia & $0.66(0.49-0.88)$ & 0.005 & $0.67(0.50-0.89)$ & 0.006 \\
\hline Diabetes & $1.12(0.82-1.54)$ & 0.474 & $1.93(1.39-2.69)$ & $<0.001$ \\
\hline Family history of CAD & $0.84(0.61-1.15)$ & 0.281 & $1.51(1.11-2.04)$ & 0.009 \\
\hline NCEP & $1.41(1.13-1.76)$ & 0.003 & $1.96(1.61-2.40)$ & $<0.001$ \\
\hline \multicolumn{5}{|l|}{ Low risk } \\
\hline \multicolumn{5}{|l|}{ Intermediate risk } \\
\hline \multicolumn{5}{|l|}{ High risk } \\
\hline Chest pain ${ }^{\mathrm{b}}$ & $0.80(0.57-1.11)$ & 0.184 & $0.54(0.39-0.76)$ & $<0.001$ \\
\hline Dyspnea $^{c}$ & $1.68(1.20-2.36)$ & 0.003 & $2.36(1.68-3.31)$ & $<0.001$ \\
\hline SIS & $1.13(1.08-1.18)$ & $<0.001$ & $1.22(1.16-1.28)$ & $<0.001$ \\
\hline Age & $1.07(1.06-1.09)$ & $<0.001$ & $1.08(1.07-1.09)$ & $<0.001$ \\
\hline$\%$ SIS & $1.02(1.01-1.02)$ & $<0.001$ & $1.03(1.02-1.03)$ & $<0.001$ \\
\hline aSIS & $1.72(1.20-2.45)$ & 0.003 & $3.84(2.59-5.70)$ & $<0.001$ \\
\hline aSIS category & $1.37(1.13-1.67)$ & 0.002 & $1.59(1.39-1.83)$ & $<0.001$ \\
\hline
\end{tabular}

${ }^{\mathrm{a}} n=4453$
${ }^{\mathrm{b}} n=4584$
${ }^{\mathrm{c}} n=4405$

Table 5 Cox models for mortality in patients with obstructive CAD

\begin{tabular}{|c|c|c|c|c|c|c|c|c|c|}
\hline & $\begin{array}{l}\text { Hazard ratios } \\
(95 \% \mathrm{CI})\end{array}$ & $p$ value & $\begin{array}{l}\text { Global } \\
\text { Chi- } \\
\text { square }\end{array}$ & $\begin{array}{l}\text { Harrell } C \text {-statis- } \\
\text { tic }(95 \% \mathrm{CI})\end{array}$ & NRI & NRI $p$ value & IDI & IDI $p$ value & Relative IDI \\
\hline Clinical & & & 16.38 & $\begin{array}{l}0.560(0.523- \\
0.659)\end{array}$ & - & - & - & - & - \\
\hline $\begin{array}{l}\text { Smoker/ex- } \\
\text { smoker }\end{array}$ & $1.57(1.17-2.11)$ & 0.003 & & & & & & & \\
\hline Dyslipidemia & $0.64(0.48-0.86)$ & 0.003 & & & & & & & \\
\hline Clinical + aSIS ${ }^{\mathrm{a}}$ & & & 25.85 & $\begin{array}{l}0.599(0.548- \\
0.651)\end{array}$ & $\begin{array}{l}0.122 \\
\quad(-0.025- \\
0.269)\end{array}$ & 0.105 & $\begin{array}{l}0.003 \\
(0.000- \\
0.005)\end{array}$ & 0.031 & $33.88 \%$ \\
\hline $\begin{array}{l}\text { Smoker/ex- } \\
\text { smoker }\end{array}$ & $1.48(1.10-2.00)$ & 0.010 & & & & & & & \\
\hline Dyslipidemia & $0.60(0.44-0.80)$ & 0.001 & & & & & & & \\
\hline $\mathrm{aSIS}^{\mathrm{a}}$ & $1.79(1.25-2.58)$ & 0.002 & & & & & & & \\
\hline
\end{tabular}

Only variables with a univariate $p<0.05$ including all patients were included in the Cox regression model

${ }^{\mathrm{a}}$ Continuous variable

findings from this study placed in the context of available CT data would suggest that higher aSIS warrants closer clinical surveillance and follow-up, and more aggressive institution of preventative measures including lifestyle modifications, more aggressive risk factor control, and consideration of statin therapy $[5,11,29,30,33]$.

\section{Limitations}

Ideally direct measures of plaque progression would provide us with information regarding true rates of change and how they may be attenuated with medical therapy. In the absence of such tests, aSIS may be a reasonable marker 
Table 6 Cox models for mortality in patients with non-obstructive CAD

\begin{tabular}{|c|c|c|c|c|c|c|c|c|c|}
\hline & $\begin{array}{l}\text { Hazard ratios } \\
(95 \% \mathrm{CI})\end{array}$ & $p$ value & $\begin{array}{l}\text { Global } \\
\text { Chi- } \\
\text { square }\end{array}$ & $\begin{array}{l}\text { Harrell } C \text {-statistic } \\
(95 \% \mathrm{CI})\end{array}$ & NRI & NRI $p$ value & IDI & IDI $p$ value & Relative IDI \\
\hline Clinical & & & 66.45 & $\begin{array}{l}0.679(0.632- \\
0.726)\end{array}$ & - & - & - & - & - \\
\hline $\begin{array}{l}\text { Smoker/ex- } \\
\text { smoker }\end{array}$ & $1.71(1.26-2.32)$ & $<0.001$ & & & & & & & \\
\hline Hypertension & $2.18(1.60-2.98)$ & $<0.001$ & & & & & & & \\
\hline Dyslipidemia & $0.58(0.43-0.77)$ & 0.001 & & & & & & & \\
\hline Diabetes & $1.74(1.25-2.44)$ & 0.001 & & & & & & & \\
\hline $\begin{array}{l}\text { Family history } \\
\text { of CAD }\end{array}$ & $1.48(1.09-2.01)$ & 0.013 & & & & & & & \\
\hline Clinical + aSIS ${ }^{\mathrm{a}}$ & & & 96.83 & $\begin{array}{l}0.723(0.680- \\
0.765)\end{array}$ & $\begin{array}{l}0.487 \\
\quad(0.342- \\
0.630)\end{array}$ & $<0.001$ & $\begin{array}{l}0.001 \\
(0.000- \\
0.002)\end{array}$ & 0.039 & $52.60 \%$ \\
\hline $\begin{array}{l}\text { Smoker/ex- } \\
\text { smoker }\end{array}$ & $1.63(1.20-2.22)$ & 0.002 & & & & & & & \\
\hline Hypertension & $2.07(1.51-2.83)$ & $<0.001$ & & & & & & & \\
\hline Dyslipidemia & $0.53(0.40-0.71)$ & $<0.001$ & & & & & & & \\
\hline Diabetes & $1.64(1.17-2.30)$ & 0.004 & & & & & & & \\
\hline $\begin{array}{l}\text { Family history } \\
\text { of CAD }\end{array}$ & $1.43(1.05-1.94)$ & 0.024 & & & & & & & \\
\hline $\operatorname{aSIS}^{\mathrm{a}}$ & $3.48(2.33-5.18)$ & $<0.001$ & & & & & & & \\
\hline
\end{tabular}

Only variables with a univariate $p<0.05$ including all patients were included in the Cox regression model

${ }^{\mathrm{a} C}$ Continuous variable

of premature atherosclerosis that is extensive for age. Age was removed from the multivariable analysis to avoid collinearity with aSIS, as age is part of the score; however, in the univariable analysis, aSIS score was a superior predictor of mortality than age, SIS or \%SIS alone with much higher hazard ratios. Further studies are needed to better understand how such measures can be used to guide medical therapy. Although aSIS was prognostic for MACE in our previous study, not all CONFIRM centers were able to collect MACE. Therefore, all-cause mortality was the pre-specified primary end point for the CONFIRM registry [12]. Breakup of cause of death was not available from the query of the National Death Index for US sites.

\section{Conclusion}

aSIS may be a surrogate marker for vascular age and has independent and incremental prognostic value for all-cause mortality over traditional risk factors, obstructive CAD on CCTA. Further studies are needed to understand how it can be incorporated into clinical practice and how it might direct preventative measures.

Acknowledgements The assistance of the Mayo Clinic Medical illustrations Unit with the figures is acknowledged with much thanks.
Benjamin Chow receives research support from CV Diagnostix, and research and educational support from TeraRecon Inc. and holds the Saul \& Edna Goldfarb Research Chair in Cardiac Imaging. There is no funding associated with this work.

\section{Compliance with ethical standards}

Conflict of interest There is no funding associated with this work. Dr. Min received the modest speakers' bureau and medical advisory board compensation and significant research support from GE Healthcare. Dr. Achenbach received grant support from Siemens and Bayer Schering Pharma and has served as a consultant for Servier. Dr. AlMallah received support from the American Heart Association, BCBS Foundation of Michigan, and Astellas. Dr. Cademartiri received grant support from GE Healthcare and has served on the Speakers' Bureau of Bracco and as a consultant for Servier; Dr. Maffei received grant support from GE Healthcare. Dr. Chinnaiyan received grant support from Bayer Pharma and Blue Cross Blue Shield Blue Care MI. Dr. Chow received research and fellowship support from GE Healthcare, research support from Pfizer and AstraZeneca, and educational support from TeraRecon. Dr. Hausleiter received a research grant from Siemens Medical Systems. Dr. Kaufmann received institutional research support from GE Healthcare and grant support from Swiss National Science Foundation. Dr. Maffei received grant support from GE Healthcare Dr. Raff received grant support from Siemens, Blue Cross Blue Shield Blue Care MI, and Bayer Pharma. Dr. Leipsic has received research support and serves on the speaker's bureau for GE Healthcare. All other authors have reported that they have no relationships relevant to the contents of this paper to disclose. 
Ethical standards All procedures performed in studies involving human participants were in accordance with the ethical standards of the institutional and/or national research committee and with the 1964 Helsinki Declaration and its later amendments or comparable ethical standards.

Informed consent Informed consent was obtained from individual participants included in the study or was waived by the institutional research board.

\section{References}

1. Taylor AJ, Cerqueira M, Hodgson JM, Mark D, Min J, O'Gara P, Rubin GD, American College of Cardiology Foundation Appropriate Use Criteria Task F, Society of Cardiovascular Computed T, American College of R, American Heart A, American Society of E, American Society of Nuclear C, North American Society for Cardiovascular I, Society for Cardiovascular A, Interventions, Society for Cardiovascular Magnetic R (2010) ACCF/SCCT/ACR/AHA/ASE/ASNC/NASCI/SCAI/SCMR 2010 appropriate use criteria for cardiac computed tomography. A report of the American College of Cardiology Foundation Appropriate Use Criteria Task Force, the Society of Cardiovascular Computed Tomography, the American College of Radiology, the American Heart Association, the American Society of Echocardiography, the American Society of Nuclear Cardiology, the North American Society for Cardiovascular Imaging, the Society for Cardiovascular Angiography and Interventions, and the Society for Cardiovascular Magnetic Resonance. J Cardiovasc Comput Tomogr 4(6):407 e1-407 e33

2. Chow BJ, Wells GA, Chen L, Yam Y, Galiwango P, Abraham A, Sheth T, Dennie C, Beanlands RS, Ruddy TD (2010) Prognostic value of 64-slice cardiac computed tomography severity of coronary artery disease, coronary atherosclerosis, and left ventricular ejection fraction. J Am Coll Cardiol 55(10):1017-1028

3. Min JK, Shaw LJ, Devereux RB, Okin PM, Weinsaft JW, Russo DJ, Lippolis NJ, Berman DS, Callister TQ (2007) Prognostic value of multidetector coronary computed tomographic angiography for prediction of all-cause mortality. J Am Coll Cardiol 50(12):1161-1170

4. Lin FY, Shaw LJ, Dunning AM, Labounty TM, Choi JH, Weinsaft JW, Koduru S, Gomez MJ, Delago AJ, Callister TQ, Berman DS, Min JK (2011) Mortality risk in symptomatic patients with nonobstructive coronary artery disease: a prospective 2-center study of 2,583 patients undergoing 64-detector row coronary computed tomographic angiography. J Am Coll Cardiol 58(5):510-519

5. Bittencourt MS, Hulten E, Ghoshhajra B, O'Leary D, Christman MP, Montana P, Truong QA, Steigner M, Murthy VL, Rybicki FJ, Nasir K, Gowdak LH, Hainer J, Brady TJ, Di Carli MF, Hoffmann U, Abbara S, Blankstein R (2014) Prognostic value of nonobstructive and obstructive coronary artery disease detected by coronary computed tomography angiography to identify cardiovascular events. Circ Cardiovasc Imaging 7(2):282-291

6. Hadamitzky M, Distler R, Meyer T, Hein F, Kastrati A, Martinoff S, Schomig A, Hausleiter J (2011) Prognostic value of coronary computed tomographic angiography in comparison with calcium scoring and clinical risk scores. Circ Cardiovasc Imaging 4(1):16-23

7. Ayoub C, Erthal F, Abdelsalam MA, Murad MH, Wang Z, Erwin PJ, Hillis GS, Kritharides L, Chow BJW (2017) Prognostic value of segment involvement score compared to other measures of coronary atherosclerosis by computed tomography: a systematic review and meta-analysis. J Cardiovasc Comput Tomogr 11(4):258-267

8. Raggi P, Callister TQ, Shaw LJ (2004) Progression of coronary artery calcium and risk of first myocardial infarction in patients receiving cholesterol-lowering therapy. Arterioscler Thromb Vasc Biol 24(7):1272-1277

9. Waters D, Craven TE, Lesperance J (1993) Prognostic significance of progression of coronary atherosclerosis. Circulation 87(4):1067-1075

10. Nicholls SJ, Hsu A, Wolski K, Hu B, Bayturan O, Lavoie A, Uno K, Tuzcu EM, Nissen SE (2010) Intravascular ultrasoundderived measures of coronary atherosclerotic plaque burden and clinical outcome. J Am Coll Cardiol 55(21):2399-2407

11. Ayoub C, Yam Y, Chen L, Arasaratnam P, Chow CK, Hillis GS, Kritharides L, Chow BJ (2016) The prognostic value of percentage total plaque score adjusted to age: a potential marker of coronary vascular age. Angiology 7(10):916-926

12. Min JK, Dunning A, Lin FY, Achenbach S, Al-Mallah MH, Berman DS, Budoff MJ, Cademartiri F, Callister TQ, Chang HJ, Cheng V, Chinnaiyan KM, Chow B, Delago A, Hadamitzky M, Hausleiter J, Karlsberg RP, Kaufmann P, Maffei E, Nasir K, Pencina MJ, Raff GL, Shaw LJ, Villines TC (2011) Rationale and design of the CONFIRM (COronary CT Angiography EvaluatioN For Clinical Outcomes: an InteRnational Multicenter) Registry. J Cardiovasc Comput Tomogr 5(2):84-92

13. National Cholesterol Education Program Expert Panel on Detection, Evaluation and Treatment of High Blood Cholesterol in Adults Adult Treatment Panel III (2002) Detection, evaluation, and treatment of high blood cholesterol in adults (adult treatment panel III) final report. Circulation 106(25):3143-3421

14. Chaitman BR, Bourassa MG, Davis K, Rogers WJ, Tyras DH, Berger R, Kennedy JW, Fisher L, Judkins MP, Mock MB, Killip $\mathrm{T}$ (1981) Angiographic prevalence of high-risk coronary artery disease in patient subsets (CASS). Circulation 64(2):360-367

15. Gibbons RJ, Chatterjee K, Daley J, Douglas JS, Fihn SD, Gardin JM, Grunwald MA, Levy D, Lytle BW, O'Rourke RA, Schafer WP, Williams SV, Ritchie JL, Cheitlin MD, Eagle KA, Gardner TJ, Garson A Jr, Russell RO, Ryan TJ, Smith SC Jr (1999) ACC/ AHA/ACP-ASIM guidelines for the management of patients with chronic stable angina: a report of the American College of Cardiology/American Heart Association Task Force on Practice Guidelines (Committee on Management of Patients With Chronic Stable Angina). J Am Coll Cardiol 33(7):2092-2197

16. Leipsic J, Abbara S, Achenbach S, Cury R, Earls JP, Mancini GJ, Nieman K, Pontone G, Raff GL (2014) SCCT guidelines for the interpretation and reporting of coronary CT angiography: a report of the Society of Cardiovascular Computed Tomography Guidelines Committee. J Cardiovasc Comput Tomogr 8(5):342-358

17. Agatston AS, Janowitz WR, Hildner FJ, Zusmer NR, Viamonte M Jr, Detrano R (1990) Quantification of coronary artery calcium using ultrafast computed tomography. J Am Coll Cardiol 15(4):827-832

18. Pencina MJ, D'Agostino RB (2004) Overall C as a measure of discrimination in survival analysis: model specific population value and confidence interval estimation. Stat Med 23(13):2109-2123

19. Pencina MJ, D'Agostino RB Sr, D'Agostino RB Jr, Vasan RS (2008) Evaluating the added predictive ability of a new marker: from area under the ROC curve to reclassification and beyond. Stat Med 27(2):157-172 (discussion 207-212)

20. Pencina MJ, D'Agostino RB Sr, Steyerberg EW (2011) Extensions of net reclassification improvement calculations to measure usefulness of new biomarkers. Stat Med 30(1):11-21

21. Pen A, Yam Y, Chen L, Dennie C, McPherson R, Chow BJ (2013) Discordance between Framingham Risk Score and atherosclerotic plaque burden. Eur Heart J 34(14):1075-1082 
22. Stone GW, Maehara A, Lansky AJ, de Bruyne B, Cristea E, Mintz GS, Mehran R, McPherson J, Farhat N, Marso SP, Parise H, Templin B, White R, Zhang Z, Serruys PW, Investigators P (2011) A prospective natural-history study of coronary atherosclerosis. $\mathrm{N}$ Engl J Med 364(3):226-235

23. Burke AP, Kolodgie FD, Farb A, Weber DK, Malcom GT, Smialek J, Virmani R (2001) Healed plaque ruptures and sudden coronary death: evidence that subclinical rupture has a role in plaque progression. Circulation 103(7):934-940

24. Proudfit WL, Bruschke VG, Sones FM Jr (1980) Clinical course of patients with normal or slightly or moderately abnormal coronary arteriograms: 10-year follow-up of 521 patients. Circulation 62(4):712-717

25. Choi TY, Li D, Nasir K, Zeb I, Sourayanezhad S, Gupta M, Hacioglu Y, Mao SS, Budoff MJ (2013) Differences in coronary atherosclerotic plaque burden and composition according to increasing age on computed tomography angiography. Acad Radiol 20(2):202-208

26. Tota-Maharaj R, Blaha MJ, Rivera JJ, Henry TS, Choi EK, Chang SA, Yoon YE, Chun EJ, Choi SI, Blumenthal RS, Chang HJ, Nasir $\mathrm{K}$ (2012) Differences in coronary plaque composition with aging measured by coronary computed tomography angiography. Int $\mathbf{J}$ Cardiol 158(2):240-245

27. Enos WF, Holmes RH, Beyer J (1986) Landmark article, July 18, 1953: coronary disease among United States soldiers killed in action in Korea. Preliminary report. By William F. Enos, Robert H. Holmes and James Beyer. JAMA 256(20):2859-2862

28. Kaski JC, Chester MR, Chen L, Katritsis D (1995) Rapid angiographic progression of coronary artery disease in patients with angina pectoris. The role of complex stenosis morphology. Circulation 92(8):2058-2065

29. Cheezum MK, Hulten EA, Smith RM, Taylor AJ, Kircher J, Surry L, York M, Villines TC (2013) Changes in preventive medical therapies and cv risk factors after CT angiography. JACC Cardiovasc Imaging 6(5):574-581

30. Uretsky S, Rozanski A, Supariwala A, Thotakura G, Kanneganti S, Satyanarayana N, Mantrala P, Yeturi SR, Peters MR, Fisher E, Wolff SD (2013) Clinical outcomes following a strategy of optimized medical management and selective "downstream" procedures following coronary computed tomography angiography. Int J Cardiol 165(3):468-473

31. Rozanski A, Gransar H, Shaw LJ, Kim J, Miranda-Peats L, Wong ND, Rana JS, Orakzai R, Hayes SW, Friedman JD, Thomson LE, Polk D, Min J, Budoff MJ, Berman DS (2011) Impact of coronary artery calcium scanning on coronary risk factors and downstream testing the EISNER (Early Identification of Subclinical Atherosclerosis by Noninvasive Imaging Research) prospective randomized trial. J Am Coll Cardiol 57(15):1622-1632

32. Chow BJ, Small G, Yam Y, Chen L, McPherson R, Achenbach S, Al-Mallah M, Berman DS, Budoff MJ, Cademartiri F, Callister TQ, Chang HJ, Cheng VY, Chinnaiyan K, Cury R, Delago A, Dunning A, Feuchtner G, Hadamitzky M, Hausleiter J, Karlsberg RP, Kaufmann PA, Kim YJ, Leipsic J, LaBounty T, Lin F, Maffei E, Raff GL, Shaw LJ, Villines TC, Min JK, Investigators C (2015) Prognostic and therapeutic implications of statin and aspirin therapy in individuals with nonobstructive coronary artery disease: results from the CONFIRM (COronary CT Angiography EvaluatioN For Clinical Outcomes: an InteRnational Multicenter registry) registry. Arterioscler Thromb Vasc Biol 35(4):981-989

33. Hwang IC, Jeon JY, Kim Y, Kim HM, Yoon YE, Lee SP, Kim HK, Sohn DW, Sung J, Kim YJ (2015) Statin therapy is associated with lower all-cause mortality in patients with non-obstructive coronary artery disease. Atherosclerosis 239(2):335-342

\section{Affiliations}

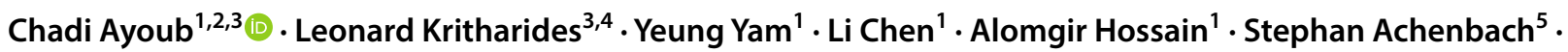
Mouaz H. Al-Mallah ${ }^{6}$. Daniele Andreini ${ }^{7}$. Daniel S. Berman ${ }^{8}$. Matthew J. Budoff . Filippo Cademartiri $^{10}$. Tracy Q. Callister ${ }^{11} \cdot$ Hyuk-Jae Chang ${ }^{12} \cdot$ Kavitha Chinnaiyan $^{13} \cdot$ Ricardo C. Cury $^{14} \cdot$ Augustin Delago $^{15}$. Allison Dunning ${ }^{16} \cdot$ Gudrun Feuchtner $^{17} \cdot$ Millie Gomez $^{18} \cdot$ Heidi Gransar $^{8} \cdot$ Martin Hadamitzky $^{19}$. Joerg Hausleiter ${ }^{19}$. Niree Hindoyan ${ }^{18}$. Philipp A. Kaufmann ${ }^{20}$. Yong-Jin Kim ${ }^{21}$. Jonathon Leipsic ${ }^{22}$. Erica Maffei ${ }^{10}$. Hugo Marques ${ }^{23}$. Gianluca Pontone ${ }^{7} \cdot$ Gilbert Raff $^{13} \cdot$ Ronen Rubinshtein $^{24} \cdot$ Leslee J. Shaw $^{25} \cdot$ Todd C. Villines $^{26}$. James K. Min ${ }^{18} \cdot$ Benjamin J. W. Chow ${ }^{1,27}$

1 Department of Medicine (Cardiology), University of Ottawa Heart Institute, 40 Ruskin Street, Ottawa, ON K1Y 4W7, Canada

2 Department of Cardiovascular Medicine, Cleveland Clinic, Cleveland, OH, USA

3 University of Sydney, Sydney, NSW, Australia

4 Department of Cardiology, Concord Hospital, Sydney Local Health District, Sydney, NSW, Australia

5 Department of Medicine, University of Erlangen, Erlangen, Germany

6 King Abdullah International Medical Research Center, King AbdulAziz Cardiac Center, Riyadh, Saudi Arabia

7 Department of Clinical Sciences and Community Health, University of Milan, Centro Cardiologico Monzino, IRCCS Milan, Milan, Italy
8 Department of Imaging, Cedars Sinai Medical Center, Los Angeles, CA, USA

9 Department of Medicine, Harbor UCLA Medical Center, Los Angeles, CA, USA

10 Cardiovascular Imaging Unit, Giovanni XXIII Hospital, Monastier, Treviso, Italy

11 Tennessee Heart and Vascular Institute, Hendersonville, TN, USA

12 Division of Cardiology, Severance Cardiovascular Hospital and Severance Biomedical Science Institute, Yonsei University College of Medicine, Seoul, South Korea

13 William Beaumont Hospital, Royal Oaks, MI, USA

14 Baptist Cardiac and Vascular Institute, Miami, FL, USA

15 Capitol Cardiology Associates, Albany, NY, USA 
16 Duke Clinical Research Institute, Durham, NC, USA

17 Department of Radiology, Medical University of Innsbruck, Innsbruck, Austria

18 Dalio Institute of Cardiovascular Imaging, Weill Cornell Medical College and New York-Presbyterian Hospital, New York, NY, USA

19 Division of Cardiology, Deutsches Herzzentrum Munchen, Munich, Germany

20 University Hospital, Zurich, Switzerland

21 Seoul National University Hospital, Seoul, South Korea

22 Department of Medicine and Radiology, University of British Columbia, Vancouver, BC, Canada
23 Department of Surgery, Curry Cabral Hospital, Lisbon, Portugal

24 Department of Cardiology, Lady Davis Carmel Medical Center, Technion-Israel Institute of Technology, Haifa, Israel

25 Division of Cardiology, Emory University School of Medicine, Atlanta, GA, USA

26 Department of Medicine, Walter Reed Medical Center, Washington, DC, USA

27 Department of Radiology, University of Ottawa, Ottawa, Canada 